\title{
A Prospective Study of Factors Influencing Wound Dehiscence after Midline Laparotomy
}

\author{
Kusum Meena ${ }^{1}$, Shadan $\mathrm{Ali}^{1}$, Awneet Singh Chawla ${ }^{2}$, Lalit Aggarwal ${ }^{1}$, Suhani Suhani ${ }^{1}$, \\ Sanjay Kumar ${ }^{1}$, Rehan Nabi Khan ${ }^{3}$ \\ ${ }^{1}$ Department of Surgery, Lady Hardinge Medical College and Smt. Sucheta Kriplani Hospital, New Delhi, India \\ ${ }^{2}$ Department of Surgery, Safdarjung Hospital, New Delhi, India \\ ${ }^{3}$ Department of Surgical Disciplines, All India Institute of Medical Sciences, New Delhi, India \\ Email: shadanali@yahoo.com
}

Received May 22, 2013; revised June 23, 2013; accepted July 1, 2013

Copyright (c) 2013 Kusum Meena et al. This is an open access article distributed under the Creative Commons Attribution License, which permits unrestricted use, distribution, and reproduction in any medium, provided the original work is properly cited.

\begin{abstract}
Aim: To evaluate the factors influencing fascial wound dehiscence after midline laparotomy in the patients of perforation peritonitis with an emphasis on measurement of "intra-abdominal" pressure (IAP) and fascial transforming growth factor-beta (TGF-beta). Methods: Hundred eligible adult patients with the diagnosis of perforation peritonitis who underwent emergency exploratory laparotomy were prospectively recruited. Forty five patients who developed midline abdominal wound dehiscence were compared with 55 patients without dehiscence. Results: The variables that were significantly associated with wound dehiscence include anemia, hypo proteinemia, duration of surgery, prolonged postoperative ileus, wound infection and postoperative pulmonary infection. Age, gender, jaundice, cause of peritonitis, wound contamination and types of surgery were non significant variables. The mean IAP value in the patients with dehiscence was significantly higher than "non-dehiscence" group $(\mathrm{p}=0.000)$. The patients with wound dehiscence strongly expressed TGF-beta on the day of burst. Conclusion: The patients of peritonitis undergoing prolonged surgery in the presence of risk factors like anemia, hypo proteinemia, postoperative ileus, wound infection and postoperative pulmonary infection have high risk of abdominal wound dehiscence.
\end{abstract}

Keywords: Laparotomy; Perforation Peritonitis; Intra-Abdominal Pressure; Abdominal Wound Dehiscence; Transforming Growth Factor

\section{Introduction}

Of all the fall outs of abdominal surgery, dehiscence of abdominal wound is easily the most notorious [1]. Profoundly distressing both to the patient and the treating surgeon, it is a common enough complication, with the morbid consequences and at times, potentially dreadful outcome [2]. Till recent, however, it has been a subject little understood with little known about its exact etiopathogenesis, there was little a surgeon could do to take preventive steps [3].

The present study has endeavored to investigate the events and contributory factors present in the pre-operative, per-operative and immediate post-operative period that facilitate the mechanical forces of disruption and impede the biological process of healing. While the disruptive mechanical forces can objectively be measured by estimating the "intra-abdominal" pressure (IAP), the impediment to the biological process of healing can be estimated by the measure of transforming growth factorbeta (TGF-beta) expression in the healing fascial wound [4]. The purpose of this study was to evaluate the factors influencing fascial wound dehiscence after midline laparotomy in the patients of perforation peritonitis with an emphasis on measurement of IAP and fascial TGF-beta.

\section{Methods}

Hundred eligible adult patients with the diagnosis of perforation peritonitis who underwent emergency exploratory laparotomy at university college hospital New Delhi India were prospectively recruited (Table 1). Standard midline incision and continuous mass closure technique was used in each case. Based on outcome 45 patients with midline abdominal wound dehiscence (study group) were compared with 55 patients without wound dehiscence (control group). This study protocol was approved by the Institutional Ethical Committees of the 
Table 1. Clinical characteristics of dehiscence and "nondehiscence” group.

\begin{tabular}{ccc}
\hline Characteristics & $\begin{array}{c}\text { Dehiscence } \\
\text { group } \\
(\mathrm{n}=45)\end{array}$ & $\begin{array}{c}\text { "Non-dehiscence" } \\
\text { group }(\mathrm{n}=55)\end{array}$ \\
Sex & $33(17-70)$ & $29(13-71)$ \\
Men & 36 & 47 \\
Women & 9 & 8 \\
Primary diagnosis & 32 & 24 \\
Enteric perforation & 8 & 14 \\
Duodenal perforation & 2 & 7 \\
Blunt abdominal trauma & 1 & 2 \\
Tubercular stricture perforation & 0 & 1 \\
$\begin{array}{c}\text { Acute intestinal obstruction } \\
\text { with gangrenous bowel }\end{array}$ & & 6 \\
Ectopic rupture & 0 & \\
Appendicular perforation & & \\
\hline
\end{tabular}

hospital. All subject signed informed consent.

Main exclusion criteria's were: age less than 12 years, patients on steroids/immunosuppressant or anticancer therapy and patients on anticoagulant therapy

The patient's nutritional status on admission was carefully determined. The patient's were considered malnourished if they had a serum protein level less than 60 $\mathrm{g} / \mathrm{l}$. Anemia was defined as hemoglobin level of less than $11 \mathrm{~g} / \mathrm{l}$. The presence of peritonitis was confirmed by presence of clinical symptoms and signs and by the purulent exudates of abdomen.

The overall hospital stay, the underlying diseases, operation time, the operative procedures performed, the factors influencing intra abdominal pressure post operatively and post operative mortality were also recorded.

\subsection{Measurement of IAP}

IAP was measured in all 100 patients from day 0 to day 8 . Readings were taken every eight hours.

IAP was first assessed clinically and was graded as normal, moderate or markedly tense abdomen. Thereafter, the IAP was measured indirectly by employing the saline fluid column manometry technique through an indwelling Foley's catheter. First described by Sedark et al. in 2002, this procedure is easy, quick and inexpensive [5].

Sixty milliliter of saline was instilled into the urinary bladder via the indwelling catheter. Zero-reference point was taken at pubic symphysis, keeping $\mathrm{Y}$ of Foley's at the symphysis. Then Foley's was connected with graduated transparent tubing. The distance at which the sterile saline settles in the tubing was taken to be the IAP in $\mathrm{cm}$ of $\mathrm{H}_{2} \mathrm{O}$.

The following grading was used to categorize the elevated IAP [6].

$$
\begin{array}{ll}
\text { Grade I: } & 15-18 \mathrm{~cm} \mathrm{H}_{2} \mathrm{O} \\
\text { Grade II: } & 18-22 \mathrm{~cm} \mathrm{H}_{2} \mathrm{O} \\
\text { Grade III: } & 22-25 \mathrm{~cm} \mathrm{H}_{2} \mathrm{O} \\
\text { Grade IV: } & 25 \mathrm{~cm} \mathrm{H}_{2} \mathrm{O} \text { or higher }
\end{array}
$$

\subsection{Measurement of TGF-Beta}

TGF-beta was measured in the fascia from the biopsy taken at the time of surgery and then on the day burst abdomen occurred (Bancroft, JD) [7]. Expressed TGFbeta protein levels were assessed as None (0) when none of the cells stained, Mild (1+) less than $10 \%$ of the cells stained, Intermediate (2+) $10 \%$ to $20 \%$ of the cells stained and Strong (3+) when more than $20 \%$ to $25 \%$ of the cells stained following the staining of tissue by immunohistochemical staining for TGF $\beta$-protein levels by employing monoclonal antibodies using the Avidin biotin complex technique. TGF- $\beta$ was localized by means of immunohistochemical reactions (Figure 1).

\subsection{Follow up}

All the patients without wound dehiscence were called one month after discharge for clinical and ultrasonographic scar evaluation.

\subsection{Statistical Analysis}

The statistical significance of these variables was determined using unpaired $t$ test, repeated measured ANOVA test and paired $t$ test. $\mathrm{P}<0.05$ was considered significant.

\section{Results}

There were 100 patients in the study, 45 patients with midline abdominal wound dehiscence and 55 patients without wound dehiscence. Wound disruption occurred

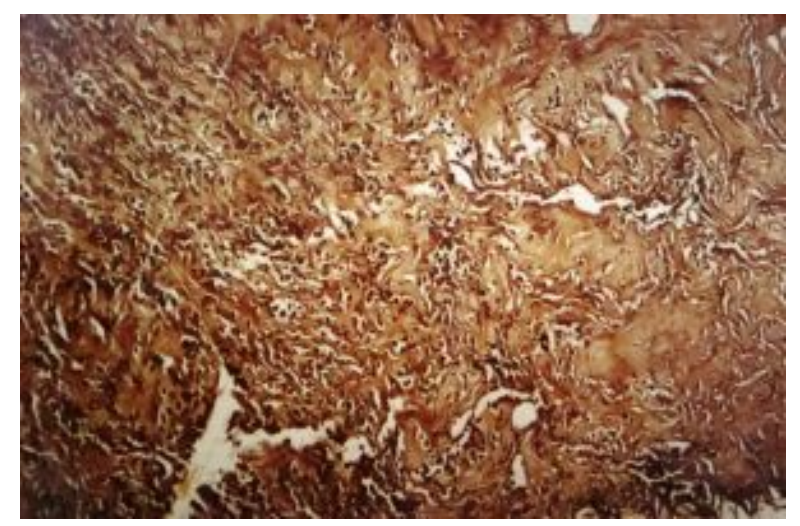

Figure 1. Photomicrograph showing strong $(3+)$ expression of TGF- $\beta$ in biopsy specimen of dehisced fascia. 
on an average of $7 \pm 2$ days post operatively (range 6 to 9). This necessitated a prolonged hospital stay on part of patients with wound dehiscence. While the stay in "nondehiscence" cases was of five to nine days, it ranged between 14 to 88 days in patients who had wound dehiscence. The mean stay in this group was 22 days. Wound dehiscence also carried a significantly higher mortality rate of $15 \%$ in comparison to that of $2 \%$ in the non dehiscence group.

IAP was assessed in each patient. The sensitivity, specificity, positive predictive value and negative predictive value of clinical examination for measurement of IAP were found to be $86 \%, 52 \%$, $88 \%$ and $47 \%$ respectively. When clinical examination was used to assess three categories of IAP range, viz. IAP between 15-18 $\mathrm{cm} \mathrm{H}_{2} \mathrm{O}, 18-22 \mathrm{~cm} \mathrm{H}_{2} \mathrm{O}$ and $22-25 \mathrm{~cm} \mathrm{H}_{2} \mathrm{O}$ and was correlated with IAP saline fluid column manometry, the weighted kappa agreement score was 0.50 . These result showed that clinical method is not an accurate tool for the assessment of IAP (Table 2).

The mean IAP value in patients with dehiscence on day 1 was $22.7 \mathrm{~cm}$ of $\mathrm{H}_{2} \mathrm{O}$, on day 2 was $21.4 \mathrm{~cm}$ of $\mathrm{H}_{2} \mathrm{O}$, and on day 3 was $20.3 \mathrm{~cm}$ of $\mathrm{H}_{2} \mathrm{O}$. The corresponding readings for "non-dehiscence" group were 19.2, 17.4, and 15.9 respectively. The difference is statistically significant with p value of 0.000 (Table 3).

Table 2. IAP measurements.

\begin{tabular}{cccc}
\hline \multirow{2}{*}{$\begin{array}{c}\text { Clinical } \\
\text { examination }\end{array}$} & Saline fluid column manometry & $\begin{array}{c}\text { Total number } \\
\text { of patients }\end{array}$ \\
\cline { 2 - 4 } IAP $>18 \mathrm{~cm}$ of $\mathrm{H}_{2} \mathrm{O}$ IAP $<18 \mathrm{~cm}$ of $\mathrm{H}_{2} \mathrm{O}$ & \\
\hline Raised & 70 & 9 & 79 \\
Normal & 11 & 10 & 21 \\
Total & 81 & 19 & 100 \\
\hline
\end{tabular}

Table 3. Values of serial measurement of IAP in the two group.

\begin{tabular}{|c|c|c|c|c|}
\hline IAP Day 1 & $\begin{array}{c}\text { Number Of } \\
\text { patients }\end{array}$ & $\begin{array}{c}\text { Mean } \\
\text { (cm of water) }\end{array}$ & $\begin{array}{l}\text { Standard } \\
\text { deviation }\end{array}$ & $\begin{array}{c}\text { Standard } \\
\text { deviation } \\
\text { mean }\end{array}$ \\
\hline $\begin{array}{l}\text { "Non-dehiscence" } \\
\text { group }\end{array}$ & 55 & 19.200 & 2.4601 & 0.3317 \\
\hline Dehiscence group & 45 & 22.7778 & 1.4443 & 0.2153 \\
\hline \multicolumn{5}{|c|}{ IAP Day 2} \\
\hline $\begin{array}{l}\text { "Non-dehiscence" } \\
\text { group }\end{array}$ & 55 & 17.4364 & 2.1323 & 0.2875 \\
\hline Dehiscence group & 45 & 21.4222 & 2.4998 & 0.2236 \\
\hline \multicolumn{5}{|c|}{ IAP Day 3} \\
\hline $\begin{array}{l}\text { "Non-dehiscence" } \\
\text { group }\end{array}$ & 55 & 15.9455 & 2.3603 & 0.3183 \\
\hline Dehiscence group & 45 & 20.3333 & 1.6652 & 0.2482 \\
\hline
\end{tabular}

$\mathrm{P}=0.000$.
The variables that were significantly associated with wound dehiscence include anemia $(p=0.001)$, hypo proteinemia ( $p=0.006)$, duration of surgery $(0.003)$. The additional postoperative factors that were found to be significant were prolonged postoperative ileus ( $\mathrm{p}=$ $0.003)$, wound infection $(p=0.000)$ and postoperative pulmonary infection $(p=0.000)$. Age $(p=0.096)$, gender $(p=0.470)$, jaundice $(p=0.644)$, cause of peritonitis ( $p$ $=0.459)$, wound contamination (0.142) and types of surgery $(p=0.261)$ were non significant variables (Table 4).

On Day 0, TGF beta was expressed in ten patients in "non-dehiscence" group and eight patients of dehiscence group. The $\mathrm{p}$ value obtained for this was 0.958 . This signified the equivalence of baseline unexpressed TGF-beta levels in these two groups on Day 0.

Forty one/forty five (91\%) patients with wound dehiscence strongly expressed TGF-beta on the day of burst as against mild presence in 8/45 patients on Day 0. The difference is statistically significant with p value of 0.000 (Table 5).

Wound dehiscence rate was $9 \%$ in the patients with three or less significant risk factors, $46 \%$ in the patients with four to seven risk factors and $100 \%$ in the patients

Table 4. Distribution of risk factors in the dehiscence and "non-dehiscence” group.

\begin{tabular}{cccc}
\hline Risk Factor & $\begin{array}{c}\text { Dehiscence } \\
\text { group }\end{array}$ & $\begin{array}{c}\text { "Non-dehiscence” } \\
\text { group }\end{array}$ & P Value \\
\hline Anemia & 32 & 23 & 0.001 \\
Jaundice & 4 & 1 & 0.644 \\
$\begin{array}{c}\text { Total Protein mean } \\
\text { g/l (SD) }\end{array}$ & $5.141(0.461)$ & $6.149(0.393)$ & 0.006 \\
$\begin{array}{c}\text { Operating time in } \\
\text { hours (SD) } \\
\text { Wound }\end{array}$ & $2.2(0.351)$ & $1.9(0.381)$ & 0.003 \\
$\begin{array}{c}\text { contamination } \\
\text { Post operative ileus } \\
\text { Post operative }\end{array}$ & 39 & 18 & 0.142 \\
pulmonary infection & 12 & 0 & 0.000 \\
\hline
\end{tabular}

Table 5. Difference between TGF-beta on day 0 and on day of burst in the wound dehiscence group.

\begin{tabular}{ccc}
\hline TGF-beta expression & Day 0 & Day of burst \\
\hline None (0) & 37 & 3 \\
Mild (1+) & 8 & 1 \\
Intermediate (2+) & 0 & 21 \\
Strong (3+) & 0 & 20 \\
Total & 45 & 45 \\
\hline
\end{tabular}

$\mathrm{P}=0.000$. 
with eight or more risk factors. The difference is statisticcally significant with $\mathrm{p}$ value of 0.000 .

Patients with seven risk factors had mortality of $25 \%$, with eight risk factors $40 \%$ and with nine or more risk factors $100 \%$.

\section{Follow up}

At one month follow up, on clinical and sonographic scar evaluation none of the patients in the "non-dehiscence" group developed incisional hernia.

\section{Discussion}

In the current study, out of 100 patients of generalized peritonitis, 45 developed wound dehiscence. The variables that were significantly associated with wound dehiscence include anemia, hypo proteinemia and duration of surgery. The postoperative factors that were found to be significant were prolonged postoperative ileus, wound infection and postoperative pulmonary infection. Age, gender, jaundice, cause of peritonitis, wound contamination and types of surgery were non significant variables. The mean IAP value was significantly higher in the dehiscence group while strong expression of TGF-beta level was observed in the healing fascial wound on the day of burst.

In our study, wound dehiscence rate was 45\%. While some retrospective studies have reported these rates between $0.2 \%$ and $10 \%$, their rates derive from patient group where few underwent emergency surgery $[8,9]$. Makela et al. reported an incidence of $10 \%$; their series include 30\% patients operated emergently [10]. Riou et al. found that 16 (51.6\%) of their 31 dehiscence patients had an emergency surgery [11]. Wound dehiscence is associated with considerable mortality. While Madson et $a l$. and Greenberg et al have reported mortality rate in the range of $10 \%$ - 30\%, the current study had a mortality of $15 \%(7 / 45)$ in the burst group and $2 \%(1 / 55)$ in the non burst group $[2,3]$. Time to dehiscence following surgery may vary considerably. The reported range is 1 to 28 days with mean of 7 days $[2,10,11]$. Abdominal wound dehiscence is associated with a prolonged hospital stay. Studies report an average stay of 45 days with a range 20 - 90 days in patients managed conservatively [3]. The mean hospitalization time was only reduced marginally to $22 \pm 10$ days and $25 \pm 15$ days, when wounds were reclosed following disruption $[2,10]$. In our study, the mean period of hospital stay of wound dehiscence patients was 22 days, with a range between 14 - 88 days. Currently preferred surgical closure technique is by a continuous running polypropylene suture using Jenkin's technique because of its simplicity, speed, low rate of wound dehiscence, and its superiority in an infected settings $[12,13]$. We also follow Jenkin's technique. In this series, we did not have a knot slippage or suture breakage in any of our patients. However, cutting through the tissue was a common problem. While a poor application of technique may be culpable, several studies emphasize the role of mechanical or biological factors operating at the wound site in causation of burst [14-16].

Measurement of IAP is critical while studying the role of mechanical factors in wound dehiscence. We tried two different approaches: clinical examination and saline fluid column manometry. The second a more objective method; allowed us to assess the accuracy of first. Girth and tenseness of the abdomen, two clinical determinant of IAP, have however been discounted by several studies $[17,18]$. They fared no better in present study. Unlike the result of Sugrue et al. (weighted kappa agreement 0.70, we did not observe a significant improvement (weighted kappa agreement 0.50 ) despite adding a third category of IAP in clinical examination [19].

Anemia and hypo proteinemia are known to impair wound healing [20]. Wound infection is a major risk factor for wound dehiscence [11,12]. Prolonged ileus and pulmonary infections are known to increase the IAP $[11,21,22]$. Both played a significant role in our series.

Patients with wound dehiscence strongly expressed TGF-beta on the day of burst as against mild presence on Day 0. Franz et al. and Mustoe et al. have also shown a peak of TGF-beta expression on five to seven day at wound site. Therefore, the wound failure in our patients is not actually a scar matrix failure [23,24]. We also attempted to correlate the fascial TGF-beta expression with IAP in dehiscence group. The mean expression of TGFbeta was found to be 2.53 in dehiscence patients with IAP $<20 \mathrm{~cm}$ of $\mathrm{H}_{2} \mathrm{O}$, and 2.48 in dehiscence patients with IAP $>20 \mathrm{~cm}$ of $\mathrm{H}_{2} \mathrm{O}$ (p value 0.786 ). Thus, wound failure occurs in the biochemically active zone adjacent to the acute wound edge where the sutures are placed. It this process that is accountable for cutting through of sutures, and was the factor responsible for wound dehiscence in the present series.

Multiple factors contributing to increase in disruptive mechanical forces were primarily responsible for abdominal wound dehiscence as the biological healing process of having scar matrix in place was found intact by revealing the strong expression of TGF-beta in the specimens of facial biopsies. A preventive attitude towards every risk factor responsible for wound breakdown at every stage before, during and after surgery should go a long way in reducing the incidence of wound dehiscence.

Limitations of the present study were small sample size and single institutional study.

\section{Conclusion}

The patients of peritonitis undergoing prolonged surgery 
in the presence of risk factors like anemia, hypo proteinemia, postoperative ileus, wound infection and postoperative pulmonary infection have high risk of abdominal wound dehiscence.

\section{REFERENCES}

[1] T. T. Irvin, C. J. Stoddard, et al., "Abdominal Wound Healing: A Prospective Clinical Study,” British Medical Journal, Vol. 2, No. 6083, 1977, pp. 351-352. doi:10.1136/bmj.2.6083.351

[2] G. Madsen, L. Fisher and P. Wara, "Burst Abdomen Clinical Features and Factors Influencing Mortality,” Danish Medical Bulletin, Vol. 39, No. 2, 1992, pp. 183-185.

[3] A. G. Greenberg and R. P. Saik, "Wound DehiscencePathophysiology and Prevention," Archives of Surgery, Vol. 114, No. 2, 1979, pp. 143-146. doi:10.1001/archsurg.1979.01370260033004

[4] P. Bradley, M. C. Pickett, P. A. Lawrence, et al., "Tensile Strength vs Healing Time for Wounds Closed under Tension," Archives of Otolaryngology-Head and Neck Surgery, Vol. 122, No. 2, 1996, pp. 565-568. doi:10.1001/archotol.1996.01890170097017

[5] M. Sedrak and K. Major, "Simple Fluid Column Manometry to Monitor for the Intra-Abdominal Pressure," Contemporary Surgery, Vol. 50, No. 5, 2002, pp. 27-29.

[6] J. M. Bruch, E. E. Moore, F. A. Moore, et al., "The Abdominal Compartment Syndrome," Surgical Clinics of North America, Vol. 76, No. 4, 1996, p. 833. doi:10.1016/S0039-6109(05)70483-7

[7] J. D. Bancroft and M. Gamble, "Theory and Practice of Histological Techniques,” Churchill Livingstone, London, 2002.

[8] G. V. Poole and N. C. Winston-Salem, "Mechanical Factors in Abdominal Wound Closure: The Prevention of Fascial Dehiscence,” Surgery, Vol. 97, No. 6, 1985, pp. 631639.

[9] R. B. Bettman and M. W. Kobak, "Relative Frequency of Evisceration after Laprotomy in Recent Years," Journal of the American Medical Association, Vol. 172, No. 16, 1960, p. 1764. doi:10.1001/jama.1960.63020160001007

[10] J. T. Makela, H. Kiviniemi, T. Juvonen, et al., "Factors Influencing Wound Dehiscence after Midline Laparotomy,” The American Journal of Surgery, Vol. 170, No. 4, 1995, p. 387. doi:10.1016/S0002-9610(99)80309-2

[11] J. P. Riou, J. R. Cohen and H. Johensen, "Factors Influencing Wound Dehiscence," The American Journal of Surgery, Vol. 163, No. 3, 1992, pp. 324-330. doi:10.1016/0002-9610(92)90014-I

[12] T. E. Bucknall and H. Ellis, “Abdominal Wound Closurea Comparison of Monofilamental Nylon and Polyglycolic
Acid,” Surgery, Vol. 89, No. 6, 1981, pp. 672-677.

[13] C. Knight and F. D. Groffen, "Abdominal Wound Closure with a Continuous Monofilament Polypropylene Suture," Archives of Surgery, Vol. 118, No. 11, 1923, pp. 1305-1308. doi:10.1001/archsurg.1983.01390110053012

[14] T. P. N. Jenkins, "The Burst Abdominal Wound: A Mechanical Approach,” British Journal of Surgery, Vol. 63, No. 11, 1976, pp. 873-876. doi:10.1002/bjs.1800631110

[15] H. Hogstorm and U. Haglund, "Post-Operative Decrease in Suture Holding Capacity in Laprotomy Wounds and Anastomoses," Acta Chirurgica Scandinavica, Vol. 151, 1985, pp. 533-535.

[16] C. A. Nelson and C. Dennis, "Wound Healing Technical Factors in the Gain of Strength in Sutured Abdominal Wounds in Rabbits," Surgery Gynecology \& Obstetrics, Vol. 93, 1951, pp. 461-467.

[17] M. A. Fusco, S. R. Martin and M. C. Chang, "Estimation of Intra-Abdominal Pressure by Bladder Pressure Measurement: Validity and Methodology,” Journal of Trauma, Vol. 50, No. 2, 2001, pp. 297-302. doi:10.1097/00005373-200102000-00016

[18] J. A. Fairclough, J. Mintowt-Czyz, I. Mackie, et al., “Abdominal Girth; An Unreliable Measure of Intra-Abdominal Bleeding,” Injury, Vol. 6, No. 2, 1984, p. 85. doi:10.1016/S0020-1383(84)80003-0

[19] M. Sugrue, A. Bauman, F. Jones, et al., "Clinical Examination is an Inaccurate Predictor of Intra-Abdominal Pressure," World Journal of Surgery, Vol. 26, No. 12, 2002, pp. 1428-1431. doi:10.1007/s00268-002-6411-8

[20] D. A. Dubay and M. G. Franz, "Acute Wound Healing: The Biology of Acute Wound Failure,” Surgical Clinics of North America, Vol. 83, No. 3, 2003, pp. 463-481. doi:10.1016/S0039-6109(02)00196-2

[21] C. Webester, L. Neumayer, R. Smout, et al., "Prognostic Models of Abdominal Wall Dehiscence after Laparotomy," Journal of Surgical Research, Vol. 109, No. 2, 2003, pp. 130-137. doi:10.1016/S0022-4804(02)00097-5

[22] A. H. P. Niggerbrugge, B. E. Hansen, J. B. Trimbos, et al., "Mechanical Factors Influencing the Incidence of Burst Abdomen," European Journal of Surgical Oncology, Vol. 161, No. 9, 1995, p. 655.

[23] M. G. Frnz, P. D. Smith, T. L. Wachtel, et al., "Fascial Incision Heals Faster than Skin: A New Model of Abdominal Wall Repair,” Surgery, Vol. 129, No. 2, 2001, pp. 203-208. doi:10.1067/msy.2001.110220

[24] T. A. Mustoe, G. F. Pierce, A. Thomason, et al., “Accelerating Healing of Incisional Wounds in Rats Induced by TGF $\beta$," Science, Vol. 237, No. 4820, 1987, pp. 13331336. doi:10.1126/science. 2442813 